\title{
Operating Line Prediction of COREX Iron-making Process Using RIST Diagram
}

\author{
C SRISHILAN, ${ }^{1)}$ Anand VIVEK ${ }^{21}$ and Ajay Kumar SHUKLA ${ }^{1) *}$ \\ 1) Department of Metallurgical and Materials Engineering, Indian Institute of Technology Madras, Chennai, 600036 India. \\ 2) Department of Metallurgical \& Materials Engineering, Jadavpur University Kolkata, 700032 India.
}

(Received on July 13, 2019; accepted on October 1, 2019)

\begin{abstract}
In the present work, the calculations of the modified operating line for the COREX process, based on the Rist diagram approach, have been performed. The operating line developed by Rist in 1960's has been modified by various researchers for improvements in the blast furnace. The idea proposed by Rist was further utilized to perform the heat balance along with the net oxygen balance for the other iron making processes. The operating line has been modified thus accounting the generated $\mathrm{H}_{2} \mathrm{O}$ and $\mathrm{CO}_{2}$ with respect to $\mathrm{Fe}$, in the process of smelting reduction of ore by coal containing volatile and moisture.
\end{abstract}

KEY WORDS: modified operating line; COREX; fuel balance.

\section{Introduction}

The shortage in the availability of the coking coal has paved the path for the development of the alternative routes of iron making, other than the traditional blast furnace route. These alternative routes can be classified into the direct reduction methods producing the direct reduced iron (DRI), and the smelting reduction methods producing the liquid hot metal. COREX is one of the commercially realized smelting reduction processes, which allows the non-coking coal to be utilized as fuel. This process, which was formerly known as Kohl Reduktion (KR) method, ${ }^{1)}$ was initially developed by German Korf Company and VAI in late 1970s, which was later industrialised by ISCOR Company of South Africa in 1989. ${ }^{2)}$ The shaft type reactor for reduction is placed above another reactor meant for smelting and gasification, are the two reactors which makes the COREX process.

The schematic diagram of the COREX process is shown in Fig. 1. The down lying melter gasifier receives the pre reduced iron ore with certain degree of metallization from the reduction shaft through the screw conveyers. The coke is charged to the melter gasifier, along with coal which gets dried, heated, devolatilized, and pyrolyzed. The coal char and coke gets combusted and gasified using the oxygen coming from the tuyeres, to generate $\mathrm{CO}$ and $\mathrm{H}_{2}$. The ore received from reduction shaft is completely reduced using these gases. The DRI is then smelted to the liquid hot metal of blast furnace grade. The melter gasifier can be divided to three zones namely, the freeboard zone, cohesive zone and raceway zone. ${ }^{3)}$ The mixing of gases, drying and devolatization of coal happens at the free-board zone. The raceway zone plays important role in coal gasification. The reduction

* Corresponding author: E-mail: shukla@iitm.ac.in

DOI: https://doi.org/10.2355/isijinternational.ISIJINT-2019-429

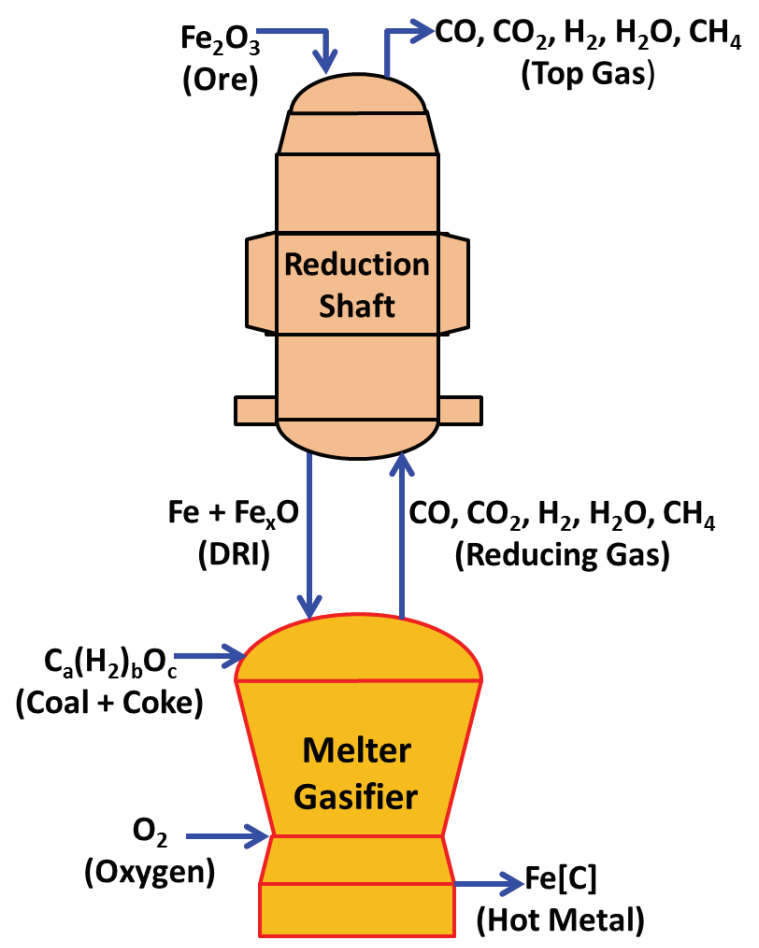

Fig. 1. Schematic diagram of COREX process. (Online version in color.)

and melting happens at the cohesive zone. The reduction shaft receives the pellets, sinters and lump ores from the top. The gas coming from the melter gasifier is cooled and introduced into the reduction shaft from the bottom. This reducing gas helps in the primary reduction of the ore. The drying and heating of the burden takes place in the top portion of the reduction shaft. The gas coming out of the COREX reduction shaft is called top gas, which is mixed with the surplus gas from melter gasifier to generate the 
potential export gas as by-product.

The COREX process has invited many researchers to study its process parameters with respect to the raw material quality. Various mathematical models of this process have been developed by researchers since its advent. The initial heat and mass balance based mathematical model was developed by Shin et $a{ }^{4)}$ in 1993. Lee et al. ${ }^{5,6)}$ developed a computer model to solve a set of ordinary differential equations to study the melter gasifier and predict the temperature inside the reactor. Pal et al. ${ }^{3,7,8)}$ has studied the melter gasifier through a steady state model based on the heat mass and momentum balance. The COREX melter gasifier was also studied through a model using thermodynamic software. ${ }^{9,10)}$ Static thermochemical modelling has been used to study the influence of metallization. ${ }^{11-14)}$ These comprehensive models have been successful in predicting the process parameters, composition of product and by product. However, the understanding of the process can be helped reasonably by a graphical model representing the heat and mass balance of the process to control the plant operations.

The operating diagram developed by Rist was used to study the blast furnace and the influence of various operating parameters on coke rate, such as the gas utilization rate, hot blast temperature, the use of pre-reduction iron ores and so on, ${ }^{15)}$ based on the essentials of oxygen transformation. The Rist operating diagram, proposed by Rist et al., ${ }^{16)}$ is of graphical representation of the steady state oxygen balance established between the iron oxide and the reducing gas in the indirect reduction zone (thermal reserve zone) of the blast furnace, where mass balance should also maintain the reduction equilibrium of iron oxide by the reducing gas. The traditional Rist diagram has been combined with the present mathematical approaches like artificial neural network, to create a hybrid model to study the blast furnace. ${ }^{17)}$ The operating line based approach of the Rist diagram known for blast furnace fuel rate calculation, ${ }^{18)}$ has also been used to study the fuel consumption of COREX process by Zhou et al. ${ }^{19)}$ The modifications in the Rist diagram of the blast furnace due to the pulverized coal injections were used for COREX process. The similar approach has been utilized to analyse the mass and heat balances of the COREX process, by Zhan et al. ${ }^{20)}$ They established a suitable modified operating diagram, which also indicated the influences of the raw materials, and the metallization rate on the fuel consumption. Theoretical assumptions of the blast furnace operations were also applied to the COREX process for the reference. Similarly Rist diagram has also been used to study the other alternative ironmaking process like ITmk3. ${ }^{21)}$ In the present work, the modified operating line equation for the COREX process has been derived and the process has been studied based on this operating line approach. The effect of metallization, fuel grades on the slope and intercepts of the operating line has been studied.

\section{Blast Furnace Rist Operating Diagram}

COREX process can assumed to be similar to the blast furnace divided into two reactors. The bottom segment of the blast furnace, where the wustite reduction zone exists, is similar to the COREX melter gasifier. The operating line for the wustite reduction zone $(1200 \mathrm{~K})$ of the blast furnace is shown in Fig. 2. The ordinate represents here the quantity of the oxygen entering into the process per unit of iron. The abscissa represents the quantity of oxygen in the gas got combined with one unit of carbon. The slope of this line can be shown in Eq. (1), which shows the number of moles of carbon got consumed per mole of Fe. The energy consumption of the blast furnace can be calculated from Eq. (2). ${ }^{22}$ The equation of the operating line of the can be derived using the Eqs. (1) and (2) is shown in Eq. (3).

Overall oxygen balance,

$$
n_{O}^{B}+\left(\frac{O}{F e}\right)^{w r z}=n_{C}^{A}\left[\frac{O}{C}\right]^{g}
$$

Bottom segment enthalpy balance,

$$
\begin{aligned}
D^{w r z}= & E_{B} n_{O}^{B}+ \\
& {\left[0.7\left(-H_{1200, \mathrm{CO}}^{f}\right)+0.3\left(-H_{1200, \mathrm{CO}_{2}}^{f}\right)\right] n_{C}^{A} }
\end{aligned}
$$

The equation of operating line for bottom segment of blast furnace,

$$
\begin{aligned}
& \left(\frac{O}{F e}\right)^{w r z}- \\
& \left\{\left(\frac{O}{F e}\right)^{w r z}-\frac{D^{w r z}+\left(\frac{O}{F e}\right)^{w r z} E_{B}}{\left[0.7\left(-H_{1200, C O}^{f}\right)+0.3\left(-H_{1200, C O_{2}}^{f}\right)\right]+E_{B}}\right\}=n_{C}^{A} \\
& {\left[\left[\frac{O}{C}\right]^{g, w r z}-\frac{\left[2\left(-H_{1200, C O}^{f}\right)+\left(-H_{1200, C O_{2}}^{f}\right)\right]}{\left[0.7\left(-H_{1200, C O}^{f}\right)+0.3\left(-H_{1200, C O_{2}}^{f}\right)\right]+E_{B}}\right]}
\end{aligned}
$$

where,

$n_{O}^{B}$, is moles of oxygen through the blast, per kg-mole of $\mathrm{Fe}$,

$\left(\frac{O}{F e}\right)$, is atomicity of the oxygen with respect to one $\mathrm{kg}$-mole of $\mathrm{Fe}$,

$E_{B}$, is enthalpy of the blast,

$D$, is heat demand,

$n_{C}^{A}$, is moles of active carbon consumed for one kg-mole

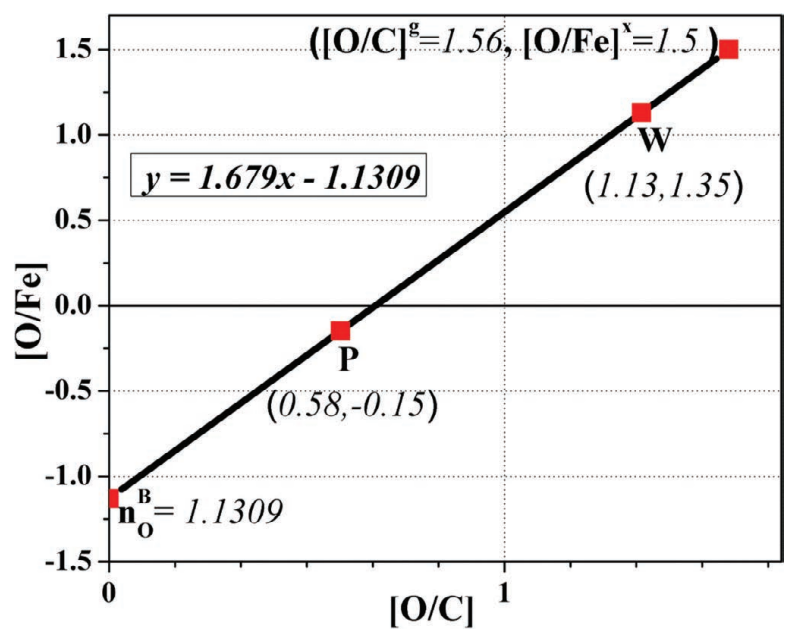

Fig. 2. Operating line of the blast furnace. (Online version in color.) 
of product $\mathrm{Fe}$,

$\left[\frac{O}{C}\right]$, is oxygen to carbon atomic ratio, and

$H_{T, \mathrm{x}}^{f}$, is heat of formation of ' $x$ ', at temperature $T$,

and, the superscripts,

$w r z$, is wustite reduction zone, and

$g$, is gas.

The point $\mathbf{P}$, known as thermal pitch point, reflects the operating condition of the process. The position of this point is helpful in estimating the heat consumed. The restriction point also known as chemical pitch point is represented as W. It represents $\mathrm{Fe}-\mathrm{Fe}_{\mathrm{x}} \mathrm{O}$ equilibrium with respect to the temperature and $\mathrm{CO} / \mathrm{CO}_{2}$ partial pressure. The intercept of the line on $[\mathrm{O} / \mathrm{Fe}]$ axis, represented by $n_{O}^{B}$, indicates the oxygen consumption through air blast.

\section{COREX Process Operating Line}

The pulverized coal injection in the blast furnace introduces volatile matter, specifically the hydrogen as a reducing agent, into the process. This generates the requirement of the modification of the equations, which will lead to the modification of the ordinate and abscissa of the plot. ${ }^{19)}$ The similar modifications have been carried out for the COREX process. The fuel entering into the COREX melter gasifier is conceptualized as $\mathrm{C}_{\alpha}\left(\mathrm{H}_{2}\right)_{\beta} \mathrm{O}_{\gamma}$ per mole of Fe. The indirect reduction of wustite by $\mathrm{H}_{2}$ and $\mathrm{CO}$ generated from hydrogen coming from the coal volatiles and carbon present in coal and coke and secondary oxygen.

\subsection{Mass Balance}

Carbon enters the process from the fuel (coal and coke), and leaves the process as $\mathrm{CO}, \mathrm{CO}_{2}$ and $\mathrm{CH}_{4}$ in the top gas. The carbon entering in the form of carbonates is not considered. Thus, the resulting the equation for net carbon balance is,

$$
n_{\mathrm{CO}}^{r g}+n_{\mathrm{CO}_{2}}^{r g}+n_{\mathrm{CH}_{4}}^{r g}+\left(\frac{n_{\mathrm{C}}}{n_{\mathrm{Fe}}}\right)=\alpha \cdot n^{I}
$$

Oxygen enters into the process from the tuyere, and secondary burners, as $\mathrm{O}_{2}$, and as oxide of $\mathrm{Fe}$ in ore. Oxygen leaves the process in the form of top gas as $\mathrm{CO}, \mathrm{CO}_{2}$, and $\mathrm{H}_{2} \mathrm{O}$. The oxygen coming from the other oxides and carbonates are not considered neglecting the oxygen leaving in the form of oxides in slag. The resulting equation for stoichiometric oxygen balance is,

$$
n_{O}^{B}+1.056 x_{\mathrm{Fe}_{x} \mathrm{O}}+\gamma \cdot n^{I}=n_{\mathrm{CO}}^{r g}+2 . n_{\mathrm{CO}_{2}}^{r g}+n_{\mathrm{H}_{2} \mathrm{O}}^{r g}
$$

Hydrogen enters the process from fuels in the form of moisture and volatiles. Hydrogen leaves the process in the form of top gas, as $\mathrm{H}_{2}, \mathrm{H}_{2} \mathrm{O}$, and $\mathrm{CH}_{4}$. The equation for hydrogen balance,

$$
\beta . n^{I}=n_{\mathrm{H}_{2}}^{r g}+n_{\mathrm{H}_{2} \mathrm{O}}^{r g}+2 n_{\mathrm{CH}_{4}}^{r g}
$$

\subsection{Energy Balance}

The overall energy balance for the COREX process can be summarized as the heat required and heat generated. The heat is consumed as sensible heat of hot metal and heat for the combustion fuel in the form of hydroxide and carbon.
The heat loss from the furnace and the heat of endothermic reduction of other oxides is not considered. The energy is produced by combustion of fuel, and enthalpy of $\mathrm{O}_{2}$. The heat balance equation of the melter gasifier,

$$
\Delta H_{\text {demand }}=\Delta H_{\text {supply }}
$$

The heat demand for the system is composed of (i) heat demand for formation and mixing of hot metal $\left(\Delta H_{H M}\right)$, and of slag $\left(\Delta H_{S L}\right)$; (ii) heat leaving the melter gasifier with the reducing gas; (iii) heat required by endothermic reactions $\left(\Delta H_{E R}\right)$; (iv) heat for drying $\left(\Delta H_{d r y}\right)$ and devolatilization of coal $\left(\Delta H_{D V C}\right)$; (v) miscellaneous heat losses $\left(\Delta H_{\text {loss }}\right)$. Whereas, the heat is supplied to the melter gasifier in the form of (i) sensible heat of the DRI entering the melter gasifier $\left(\Delta H_{D R I}\right)$, (ii) heat generated from coal combustion $\left(\Delta H_{c c}\right)$ and from post combustion $\left(\Delta H_{p c}\right)$.

Or,

$$
\begin{aligned}
& \Delta H_{H M}+\Delta H_{S L}+\Delta H_{E R}+\Delta H_{D V C}+\Delta H_{\text {dry }}+\Delta H_{\text {loss }} \\
& +\Delta H_{R G}=\Delta H_{c c}+\Delta H_{p c}+\Delta H_{D R I}
\end{aligned}
$$

Or,

$$
\begin{aligned}
& \sum n_{r g} \cdot Q_{r g}-n_{C O}^{r g} \cdot Q_{C O}^{c c}-n_{C O_{2}}^{r g} \cdot Q_{C O_{2}}^{c c}=\Delta H_{p c}+\Delta H_{D R I}- \\
& \left(\Delta H_{H M}+\Delta H_{S L}+\Delta H_{E R}+\Delta H_{D V C}+\Delta H_{d r y}+\Delta H_{\text {loss }}\right)
\end{aligned}
$$

Or,

$\sum n_{r g}\left[1-\varphi_{C O}^{r g} \cdot\left(\frac{Q_{C O}^{c c}}{Q_{r g}}\right)-\varphi_{\mathrm{CO}_{2}}^{r g} \cdot\left(\frac{Q_{\mathrm{CO}_{2}}^{c c}}{Q_{r g}}\right)\right]=$

$\left[\frac{\Delta H_{p c}+\Delta H_{D R I}-\left(\Delta H_{H M}+\Delta H_{S L}+\Delta H_{E R}+\Delta H_{D V C}+\Delta H_{d r y}+\Delta H_{l o s s}\right)}{Q_{r g}}\right]$

$$
\begin{aligned}
& \text { Or, } \\
& \sum n_{r g} \\
& {\left[\left\{\varphi_{C O}^{r g} \cdot\left(\frac{Q_{C O}^{c c}}{Q_{r g}}\right)-\varphi_{C O_{2}}^{r g} \cdot\left(\frac{Q_{C O_{2}}^{c c}}{Q_{r g}}\right)+\left(\frac{n_{C O}^{r g}+n_{H_{2} O}^{r g}+n_{C H_{4}}^{r g}}{\sum n_{r g}+2 \cdot n_{C H_{4}}^{r g}}\right)\right\}-\left\{1+\frac{n_{C O}^{r g}+n_{H_{2} O}^{r g}+n_{C H_{4}}^{r g}}{\sum n_{r g}+2 . n_{C H_{4}}^{r g}}\right\}\right]} \\
& =\left[\frac{-\Delta H_{p c}-\Delta H_{D R I}+\left(\Delta H_{H M}+\Delta H_{S L}+\Delta H_{E R}+\Delta H_{D V C}+\Delta H_{d r y}+\Delta H_{l o s s}\right)}{Q_{r g}}\right]
\end{aligned}
$$

The above equation obtained from the heat balance calculations, can be written in the form of equation of straight line, by adding and subtracting $1.056 x_{\mathrm{Fe}_{x} \mathrm{O}}$ (the atomicity of oxygen in ore coming from reduction shaft) from RHS, will result the equation of straight line in the form of $\boldsymbol{m}\left[\left(\boldsymbol{x}_{\boldsymbol{P}}-\boldsymbol{x}_{\boldsymbol{K}}\right)\right]=\left(\boldsymbol{y}_{\boldsymbol{P}}-\boldsymbol{y}_{\boldsymbol{K}}\right)$, with $\sum n_{r g}$ as slope, and passing through $\left(1.056 x_{F_{x} O},\left(1+\frac{n_{C O}^{r g}+n_{H_{2} O}^{r g}+n_{C H_{4}}^{r g}}{\sum n_{r g}+2 . n_{C H_{4}}^{r g}}\right)\right)$.

Or,

$\sum n_{r g}\left[\left\{\varphi_{C O}^{r g} \cdot\left(\frac{Q_{C O}^{c c}}{Q_{r g}}\right)-\varphi_{C O_{2}}^{r g} \cdot\left(\frac{Q_{C O_{2}}^{c c}}{Q_{r g}}\right)+\left(\frac{n_{C O}^{r g}+r_{H_{2} O}^{r g}+n_{C H_{4}}^{r g}}{\sum n_{r g}+2 . n_{C H_{4}}^{r g}}\right)\right\}-\left\{1+\frac{n_{C O}^{r g}+n_{H_{2},}^{r g}+n_{C H_{4}}^{r g}}{\sum n_{r g}+2 . n_{C H_{4}}^{r g}}\right\}\right]=$
$\left[\left\{1.05 x_{F e O}+\frac{-\Delta H_{P c}-\Delta H_{D R l}+\left(\Delta H_{H M}+\Delta H_{S L}+\Delta H_{E R}+\Delta H_{D V C}+\Delta H_{d r y}+\Delta H_{l o s s}\right)}{Q_{r g}}\right\}-1.05 x_{F e O}\right]$

where,

$n_{a}^{b}$, is kg-moles of $a$ in $b$ per kg-mole of product Fe,

$n^{I}$, is kg-moles of fuel charged per kg-mole of product Fe, $n_{O}^{B}$, is moles of oxygen through the blast, per kg-mole 
of $\mathrm{Fe}$,

$\left(\frac{O}{F e}\right)$, is atomicity of the oxygen with respect to one kg-mole of $\mathrm{Fe}$,

$\sum n_{r g}$, is the total moles of reducing gas per kg-mole of product $\mathrm{Fe}$,

$x_{\mathrm{Fe}_{\mathrm{x}} \mathrm{O}}$, shows the mole fraction of $\mathrm{Fe}_{\mathrm{x}} \mathrm{O}$ in iron oxide from reduction shaft, and

$\alpha, \beta$, and $\gamma$, shows the moles of carbon atoms, hydrogen molecule, and oxygen atoms respectively in the fuel, conceptualized as $\mathrm{C}_{\alpha}\left(\mathrm{H}_{2}\right)_{\beta} \mathrm{O}_{\gamma}$ per mole of Fe,

and the superscripts,

$r g$, represents the gas from the melter gasifier

\subsection{Graphical Representation}

The graphical representation of this equation of the operating line is possible by calculating, each term in the Eqs. (4)-(7), using the actual plant data. The oxygen is considered to enter at $315 \mathrm{~K}$, the ore entering the melter gasifier and reducing gas entering the reduction shaft at $1173 \mathrm{~K}$. The final reduction of wustite for the reduction shaft is considered at $1073 \mathrm{~K}$ to obtain the chemical pitch point.

The thermal pitch point $\mathbf{P}$ reflects the operating condition of the process. The position of this point is helpful in estimating the heat consumed. The coordinates of this point $\mathrm{P}\left(x_{P}, y_{P}\right)$ is defined as,

$y_{P}=$
$\left(1.05 x_{F e O}+\frac{-\Delta H_{p c}-\Delta H_{D R I}+\left(\Delta H_{H M}+\Delta H_{S L}+\Delta H_{E R}+\Delta H_{D V C}+\Delta H_{d r y}+\Delta H_{l o s s}\right)}{Q_{r g}}\right)$

$$
\boldsymbol{x}_{\boldsymbol{P}}=\left(\varphi_{\mathrm{CO}}^{r g} \cdot\left(\frac{Q_{C O}^{c c}}{Q_{r g}}\right)-\varphi_{\mathrm{CO}_{2}}^{r g} \cdot\left(\frac{Q_{C O_{2}}^{c c}}{Q_{r g}}\right)+\left(\frac{n_{C O}^{r g}+n_{H_{2} O}^{r g}+n_{C H_{4}}^{r g}}{\sum n_{r g}+2 . n_{C_{4}}^{r g}}\right)\right)
$$

The input of the ore into the melter gasifier consists of $\mathrm{Fe}_{\mathrm{x}} \mathrm{O}$ and $\mathrm{Fe}$, the ratio being defined by the degree of metallization defines $y_{K}$. The composition of the reducing gas from the melter gasifier defines $x_{K}$. The coordinates of the point $\mathbf{K}\left(x_{K}, y_{K}\right)$, for the top of the melter gasifier is defined as,

$$
\begin{gathered}
\boldsymbol{y}_{\boldsymbol{K}}=\left(1.056 x_{\mathrm{Fe}_{x} O}\right) \\
\boldsymbol{x}_{\boldsymbol{K}}=\left(1+\frac{n_{\mathrm{CO}}^{r g}+n_{\mathrm{H}_{2} \mathrm{O}}^{r g}+n_{C H_{4}}^{r g}}{\sum n_{r g}+2 . n_{C H_{4}}^{r g}}\right) \ldots . .
\end{gathered}
$$

The point A reflects the composition of the top gas coming from the reduction shaft, and the atomicity of the oxygen in the ore charged into the reduction shaft. The coordinates of this point $\mathbf{A}\left(x_{A}, y_{A}\right)$ can similarly be defined as,

$$
\begin{gathered}
\boldsymbol{x}_{A}=\left(1+\frac{n_{\mathrm{CO}}^{t g}+n_{\mathrm{H}_{2} \mathrm{O}}^{t g}+n_{\mathrm{CH}_{4}}^{t g}}{\sum n_{r g}+2 . n_{C H_{4}}^{r g}}\right) \\
\boldsymbol{y}_{A}=\left(\frac{O}{F e}\right)^{x}=1.5 \ldots \ldots \ldots . .
\end{gathered}
$$

The restriction point, also known as chemical pitch point, represented as $\mathbf{W}$, can be calculated from the equilibrium coefficients $K_{C O}$ and $K_{\mathrm{H}_{2}}$ of the reduction reaction of wustite by $\mathrm{CO}$ and $\mathrm{H}_{2}$ respectively. The graphical representation of this point is the projection of the $\mathrm{CO} /$ $\left(\mathrm{CO}+\mathrm{CO}_{2}\right)$ and $\mathrm{H}_{2} /\left(\mathrm{H}_{2}+\mathrm{H}_{2} \mathrm{O}\right)$ value from the combination of Baur-Glaessner diagram, shown in Fig. 3(b), at the particular temperature of $1103 \mathrm{~K}$, into the $\left(\mathrm{O}+\mathrm{H}_{2}\right) /\left(\mathrm{C}+\mathrm{H}_{2}\right)$ coordinate at the ordinate value of 1.056. The coordinates of $\mathrm{W}\left(x_{W}, y_{W}\right)$, in the terms of equilibrium coefficients is defined as,

$$
\begin{array}{r}
\boldsymbol{x}_{W}=1+\left(\frac{K_{C O}}{1+K_{C O}}\right)\left(\varphi_{C O_{2}}^{r g}+\varphi_{C O}^{r g}\right)+\left(\frac{K_{H_{2}}}{1+K_{H_{2}}}\right)\left(\varphi_{H_{2} O}^{r g}+\varphi_{H_{2}}^{r g}\right) \\
\boldsymbol{y}_{W}=\left(\frac{\boldsymbol{O}}{\boldsymbol{F e}}\right)^{\boldsymbol{F e}_{\boldsymbol{x}} \boldsymbol{O}}=1.056 \ldots \ldots \ldots \ldots \ldots \ldots \ldots \ldots \ldots \ldots \ldots \ldots \ldots \ldots \ldots \ldots \ldots \ldots \ldots \ldots \ldots \ldots \ldots \ldots \ldots \ldots \ldots \ldots \ldots \ldots \ldots \ldots \ldots \ldots
\end{array}
$$

The intercept of this operating line with ordinate, shown as point $\mathbf{B}$ will reflect the net oxygen consumed by the process, which participates in the reaction and leaves as top gas. The slope of this operating line reflects the reducing gas content required for the process per unit of product Fe.

\section{Results and Discussion}

The one day data of the COREX process has been obtained from COREX plant, JSW Steel Ltd., Toranagallu, India. The raw material consumption, which is used for the calculation has been reported in Table 1. The coordinates of the operating line of the COREX, calculated using the above set of Eqs. (9)-(14), has been reported in Table 2. The operating line of the COREX process based on the calculated coordinates reported in Table 2, has successfully been plotted, and shown in Fig. 3. The combination of Baur-

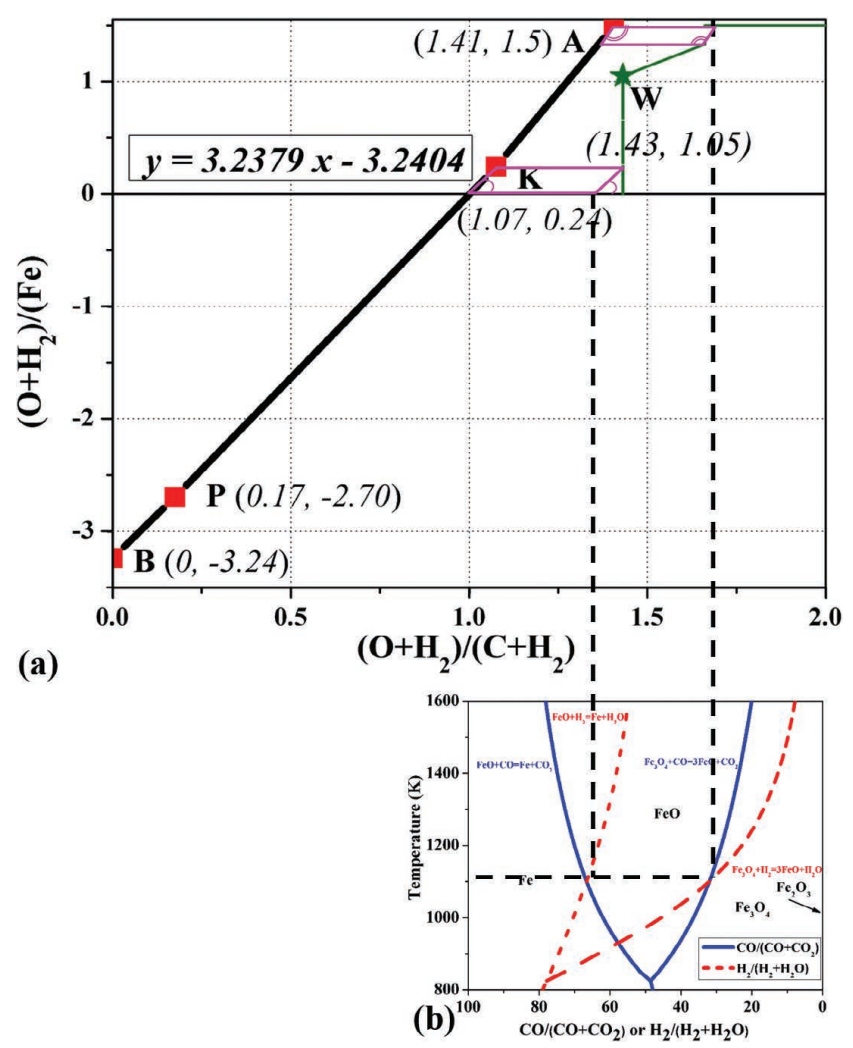

Fig. 3. (a) Calculated operating line of the COREX process with projection from (b) $\mathrm{Fe}-\mathrm{C}-\mathrm{O}$ equilibrium diagram. (Online version in color.) 
Gassener diagram, shown in Fig. 3(b), is used to project the utilization fraction over the Fig. 3(a).

Figure 4 in combination with Eqs. (19), (20). This point

Table 1. Input raw materials.

\begin{tabular}{cr}
\hline Raw materials & \multicolumn{1}{c}{ Quantity } \\
\hline Ore pellets & $1340 \mathrm{~kg} / \mathrm{THM}$ \\
Ore fines & $141 \mathrm{~kg} / \mathrm{THM}$ \\
Coal & $691 \mathrm{~kg} / \mathrm{THM}$ \\
Coke & $250 \mathrm{~kg} / \mathrm{THM}$ \\
Primary oxygen & $363 \mathrm{Nm}^{3} / \mathrm{THM}$ \\
Secondary oxygen & $126 \mathrm{Nm}^{3} / \mathrm{THM}$
\end{tabular}

Table 2. The calculated coordinates of the operating line of COREX process.

\begin{tabular}{ccr}
\hline Points & Abscissa & Ordinate \\
\hline A & 1.4068 & 1.5000 \\
K & 1.0758 & 0.2432 \\
P & 0.1750 & -2.6961 \\
B & 0.0000 & -3.2402 \\
\hline
\end{tabular}

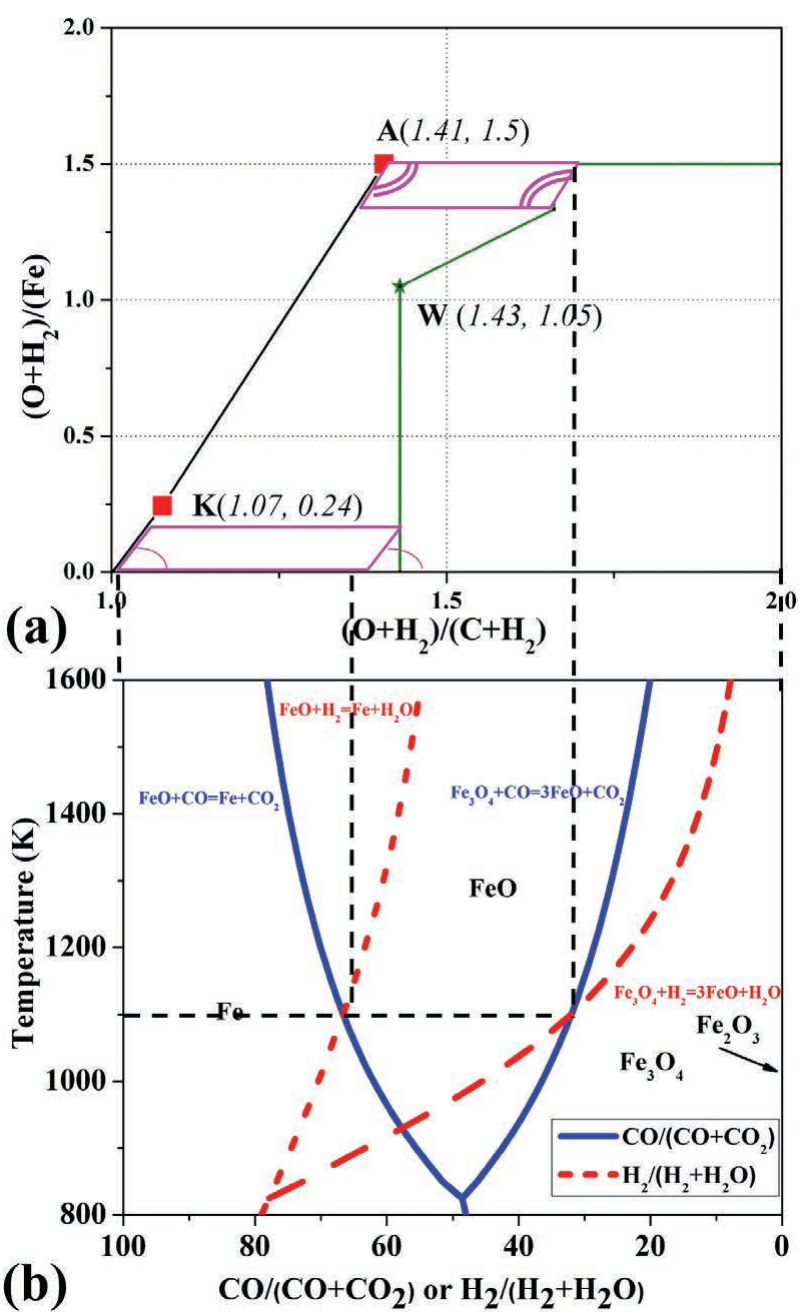

Fig. 4. Estimation of the chemical pitch point on the (a) reduction shaft portion of COREX process operating line, using (b) $\mathrm{Fe}-\mathrm{C}-\mathrm{O}$ equilibrium diagram. (Online version in color.) shifts with the changes in the reducing gas composition. The shift in the ordinate of the combination of the Baur Gassener diagram to the ordinate of the operating line diagram can be explained in terms of fraction of $\% \mathrm{CO}$ and $\% \mathrm{H}_{2}$ in the reducing gas. The utilization fraction predicted by the Baur Gassener diagram at the particular temperature for the wustite reduction is to be multiplied with $\% \mathrm{CO}$ and $\% \mathrm{H}_{2}$ respectively. The one should be added to this resulting value to obtain the exact ordinate of the chemical pitch point for the operating line. Similar exercise can also be performed for magnetite to wustite reduction.

\subsection{Variation in the Degree of Metallization}

The effect of the degree of the metallization on the slope and the intercept of the operating line have been studied as shown in Fig. 5. The slope for the melter gasifier part has found to be decreasing with an increase in the metallization, which shows the decrease in the amount of the reducing gas required. On the other hand, the less negative intercept for the higher metallization shows the decrease in the required amount of the oxygen needed to burn the

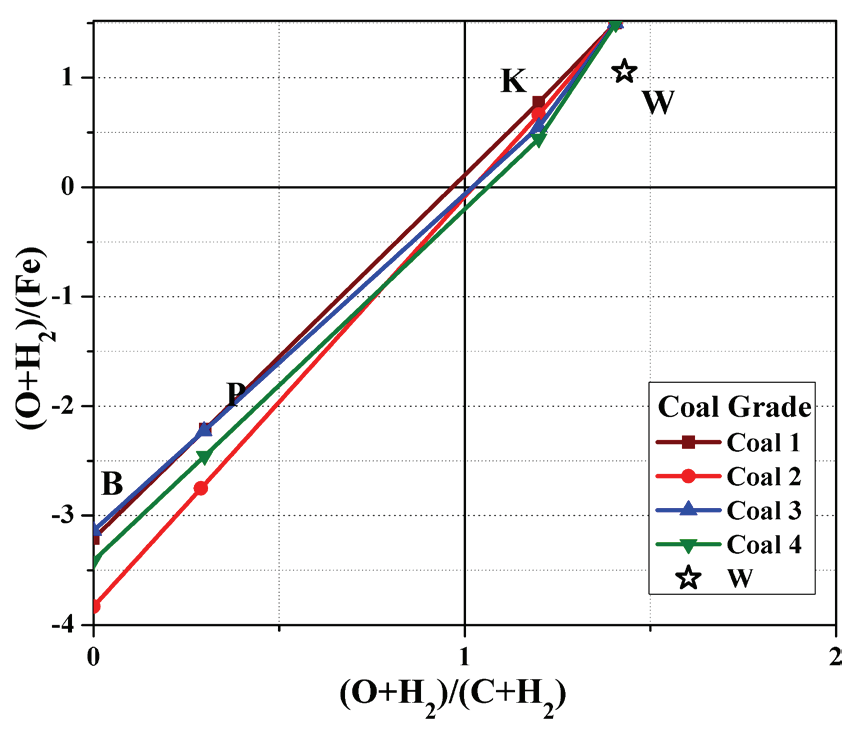

Fig. 5. Effect of degree of metallization. (Online version in color.)

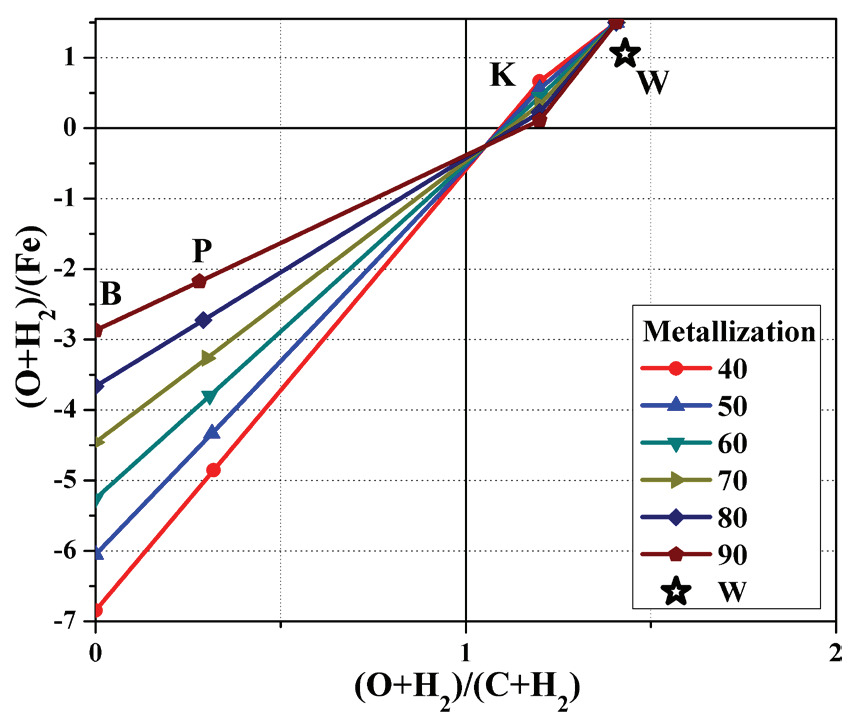

Fig. 6. Effect of coal grades. (Online version in color.) 
Table 3. Proximate analysis of different coal grades and coke.

\begin{tabular}{cccccc}
\hline Coal Grade & Ash (\%) & Volatile (\%) & Fixed C (\%) & S (\%) & Moist (\%) \\
\hline Blend & $\underline{\mathbf{0 8 . 7 7}}$ & 26.03 & 53.47 & 0.32 & 11.41 \\
Coal 1 & $\underline{\mathbf{1 1 . 3 4}}$ & 25.73 & 52.33 & 0.57 & 10.60 \\
Coal 2 & 07.31 & $\underline{\mathbf{2 6 . 7 6}}$ & 54.33 & 0.36 & 11.60 \\
Coal 3 & 08.07 & 25.85 & 53.88 & 0.32 & $\underline{\mathbf{1 2 . 2 0}}$ \\
Coal 4 & 10.74 & 17.03 & $\underline{\mathbf{6 3 . 6 3}}$ & 0.29 & 7.73 \\
\hline
\end{tabular}

lesser coal needed. The change in the slope after the melter gasifier part, and the distance of the line from the Chemical pitch point named $\mathrm{W}$, shows the kinetic limitation of the reduction shaft process.

\subsection{Effect of the Variation in the Fuel Grades}

The effect of the different grades of coal has been studied on the process using this graphical representation, as plotted in Fig. 6. The slope of the operating line and the intercept does not vary much for different coal used in the process. Nevertheless, the coal 2 with high volatile has shown the large intercept demanding high oxygen, among the other grades of coal. The proximate analysis of the coal is given in Table 3.

\section{Conclusions}

The operating line for COREX process was plotted for the plant data obtained from JSW Steel Ltd., Toranagallu, India, using the Rist operating line principle. The influence of $\mathrm{H}_{2}$ in the process was considered for this graphical model.

\section{Acknowledgement}

Authors would like to acknowledge JSW Steel Ltd., Toranagallu, Bellary, India, for providing the plant data.

\section{REFERENCES}

1) A. Chatterjee: Beyond the Blast Furnace, CRC Press Taylor \& Francis Group, Florida, (1993), 128.

2) X. L. Zhou and Z. N. Du: Adv. Mater. Res., 774-776 (2013), 1430.

3) S. Pal and A. K. Lahiri: Metall. Mater. Trans. B, 34 (2003), 103.

4) M. K. Shin, J. K. Yoon and M. Tokuda: ISIJ Int., 33 (1993), 385.

5) S. C. Lee, M. K. Shin, S. Joo and J. K. Yoon: ISIJ Int., 39 (1999), 319.

6) S. C. Lee, M. K. Shin, S. Joo and J. K. Yoon: ISIJ Int., 40 (2000), 1073.

7) S. Pal and A. K. Lahiri: ISIJ Int., 46 (2006), 58.

8) S. Pal and A. K. Lahiri: Trans. Indian Inst. Met., 59 (2006), 569.

9) B. Srivastava, S. K. Roy and P. K. Sen: Metall. Mater. Trans. B, 41 (2010), 935.

10) A. Kadrolkar, S. K. Roy and P. K. Sen: Metall. Mater. Trans. B, 43 (2012), 173.

11) Y. Qu, Z. Zou and Y. Xiao: ISIJ Int., 52 (2012), 2186.

12) S. C. Koria, M. K. Barui and L. K. Pandey: Scand. J. Metall., 28 (1999), 17.

13) S. C. Koria and M. K. Barui: Ironmak. Steelmak., 27 (2000), 348.

14) C. Srishilan and A. K. Shukla: Metall. Mater. Trans. B, 49 (2018), 388.

15) J. G. Peacey and W. G. Davenport: The Iron Blast Furnace, Theory and Practice, Pergamon Press, Oxford, (1979), 44.

16) A. Rist and N. Meysson: JOM, 19 (1967), 50.

17) F. T. P. de Medeiros, S. J. X. Noblat and A. M. F. Fileti: Ironmak. Steelmak., 34 (2007), 410.

18) D. M. Kundrat: Metall. Trans. B, 17 (1986), 705

19) X. Zhou, Z. Shi, G. Zhang, Y. Ding and X. Yang: Mater. Res. Innov., 19 (2015), 99.

20) W. L. Zhan, K. Wu, Z. J. He, Q. H. Liu and X. J. Wu: J. Iron Steel Res. Int., 22 (2015), 1078

21) S. Purohit, A. Rhamdhani and G. Brooks: Ironmak. Steelmak., 45 (2018), 978.

22) D. Mazumdar: A First Course in Iron and Steelmaking, Orient Blackswan, New Delhi, (2015), 161. 